\title{
Microstructural characteristics and mechanical properties of bronze/steel bimetallic laminated composite prepared by protective atmosphere casting process
}

\author{
Bin Liu', *Da-shan Sui ${ }^{2}$, Zhi-min Guo', Yuan-long Wang ${ }^{2}$, Xiao-lin Yang ${ }^{1}$, Guang-hong Hu , Ji-xian Zhang', \\ Chang-zeng Luo' \\ 1. Research Institute of Hydraulic Transmission, Linde Hydraulics (China) Co., Ltd., Weifang 261061, Shandong, China \\ 2. National Engineering Research Center of Die \& Mold CAD, Shanghai Jiao Tong University, Shanghai 200030, China
}

\begin{abstract}
The bonding quality of bronze/steel bimetallic laminated composite is the key factor to whether it can be used in poor working conditions. In this study, bimetallic billets were prepared by the protective atmosphere casting process. The microstructural characteristics, mechanical properties and interface bonding mechanism of the bronze/steel bimetallic composites were analyzed comprehensively through a series of microstructure analysis (inicluding OM, SEM, and EDS) and mechanical properties tests. The experimental results demonstrate that the vaporization of lead $(\mathrm{Pb})$ element in the bronze is only $0.4 \%$ in weight, and alloy elements are diffused into both sides at the interface. Moreover, the hardness in the bronze region exceeds $100.0 \mathrm{HV}$ which indicates excellent wear resistance. Tensile and shear tests indicate that the fractures mainly occur on the bronze side with the interaction of the brittle fracture of $\mathrm{Pb}$ particles and the ductile fracture of $\mathrm{Cu}-\mathrm{Sn}$ solid solution. The maximum tensile strength and shear strength reach $204.0 \mathrm{MPa}$ and $211.0 \mathrm{MPa}$, respectively. These results demonstrate that the protective atmosphere casting process is applicable for the preparation of bronze/steel bimetallic laminated composite with high quality.
\end{abstract}

Key words: protective atmosphere casting process; lead bronze; bimetallic composite; microstructure; mechanical properties

CLC numbers: TG146.1 1/142.31 Document code: A Article ID: 1672-6421(2021)05-497-08

\section{Introduction}

Metallic laminated composites are increasingly employed as engineering materials for their unique physical and mechanical properties ${ }^{[1-4]}$. This is a kind of laminated material produced by the metallurgical combinations of two or more dissimilar metals through special processes. Based on maintaining the original properties, the comprehensive performances are greatly improved ${ }^{[5-8]}$. Because of their excellent wear resistance, high thermal conductivity, and high strength,

\section{*Da-shan Sui}

Male, born in 1972, Ph.D., Associate Professor. His research interests mainly focus on alloys and composite materials engineering, including the mechanical properties and microstructure evolution of material during processing, and numerical modeling and optimization of casting and forging processes. He has published more than 50 technical papers and holds 5 invention patents of China.

E-mail: dasui@sjtu.edu.cn

Received: 2021-01-28; Accepted: 2021-07-11 bronze/steel bimetallic laminated composites are widely used in various mechanical equipment ${ }^{[9,10]}$.

Lead bronze is a kind of wear-resistant copper alloy. It not only has great thermal conductivity, good fatigue resistance, high wear resistance, and great anti-seizure properties, but also is insensitive to crack under impact loads ${ }^{[11]}$. The layered bimetallic composite prepared with steel as the basal layer and high-lead bronze as the composite layer has excellent properties, so it can be used to manufacture hydraulic components to effectively improve performance and service life ${ }^{[12-14]}$.

The powder metallurgy process is commonly employed to prepare the bronze/steel bimetallic laminated composites ${ }^{[15-18]}$, but the complex process and long production cycle lead to high cost which limits its application ${ }^{[19,20]}$. Besides, some researchers have also prepared copper/steel composites by the diffusion composite method ${ }^{[21,22]}$. However, the long heat preservation time at high temperature can easily lead 
to a massive loss of $\mathrm{Pb}$ element when high-lead copper alloys are used. In addition, the usage of direct casting methods to prepare high-lead bronze/steel composites easily leads to the segregation of $\mathrm{Pb}$ element.

The protective atmosphere casting process is a liquidsolid composite process based on the direct casting method. This process can effectively realize the preparation of bimetallic composite materials under the conditions of lower holding temperature and shorter holding time. In this study, lead bronze/45 steel bimetallic laminated composites were prepared by the protective atmosphere casting process under nitrogen protection. The distribution and diffusion state of chemical elements at the bronze/steel interface were studied by observing the interface morphology and the mechanical properties were tested by tensile, shear, and hardness experiments. Moreover, the bonding mechanism of the bimetallic interface was also discussed. The research will provide a theoretical basis for the preparation of lead bronze/45 steel bimetallic composites with a solid bonding interface and excellent mechanical properties.

\section{Experimental procedures}

\subsection{Materials and processes}

The materials used in the experiments include $\mathrm{CuPb} 15 \mathrm{Sn} 7$ lead bronze and 45 steel. The chemical compositions of the lead bronze are listed in Table 1.

Table 1: Chemical compositions of CuPb15Sn7

\begin{tabular}{ccccccccc} 
Element & $\mathrm{Cu}$ & $\mathrm{Sn}$ & $\mathrm{Pb}$ & $\mathrm{Ni}$ & $\mathrm{Zn}$ & $\mathrm{P}$ & $\mathrm{Fe}$ & Others \\
\hline Content $(\mathrm{wt} . \%)$ & 75.96 & 7.27 & 15.50 & 1.78 & $<2.0$ & $<0.1$ & $<0.2$ & $<1.0$
\end{tabular}

The specimen of 45 steel was machined into a cylinder of $\Phi 42 \mathrm{~mm} \times 45 \mathrm{~mm}$ with a groove of $\Phi 32 \mathrm{~mm} \times 7 \mathrm{~mm}$. The specimen of lead bronze was machined into a cylinder of $\Phi 30 \mathrm{~mm} \times 6 \mathrm{~mm}$. Each specimen was firstly polished to remove the oxide film on the surface, then cleaned by alcohol, acetone, $10 \% \mathrm{NaOH}$ solution, and $3 \%-5 \% \mathrm{HCl}$ solution sequentially. Subsequently, the specimen of 45 steel was immersed into $80{ }^{\circ} \mathrm{C}$ saturated borax solution for $5 \mathrm{~min}$ to cause the borax to evenly adhere to the groove wall. Finally, the bronze specimen was placed into the groove of steel, and the two specimens were assembled, as shown in Fig. 1.

The protective atmosphere casting experiments were carried out for these assembled specimens in the SG-XQL1400 protective atmosphere furnace with high purity nitrogen. The specimens were charged into the furnace when the temperature reached $900{ }^{\circ} \mathrm{C}$ with the heating speed of $10{ }^{\circ} \mathrm{C} \cdot \mathrm{s}^{-1}$, and continued to heat to $1,020^{\circ} \mathrm{C}$ and held for $5 \mathrm{~min}$, which could keep 45 steel in a solid state, while lead bronze was just heated into a liquid state. Then the specimens were taken out and cooled rapidly by blowing nitrogen, and the bronze/steel bimetallic laminated billets were prepared.

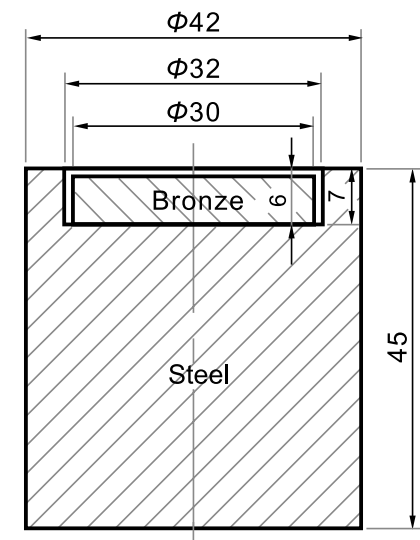

Fig. 1: Sketch of assembled specimens (unit: $\mathrm{mm}$ )

\subsection{Testing methods}

The microstructures and the fracture morphology of tensile and shear specimens of the lead bronze/45 steel composites were observed by a NOVA NanoSEM 230 scanning electron microscope (SEM). The types and distribution of alloy elements were analyzed qualitatively in the micro-area. The content of the $\mathrm{Pb}$ element in the lead bronze was quantitatively measured by iCAP7600 spectrometer (ICP) before and after the experiments. The phase fraction at the bonding interface was analyzed by D8 ADVANCE Da Vinci multi-function $\mathrm{X}$-ray diffractometer (XRD). The particle size of $\mathrm{Pb}$ element was measured and calculated by scoring method.

To study the mechanical properties of the bimetallic composites, tensile and shear specimens were machined by linear cutting machine. The bronze/steel bimetallic composite was prepared three times. Two tensile specimens and two shear specimens were taken from each prepared sample. The special fixtures were designed and produced for the tensile and shear tests, as shown in Fig. 2. The tensile and shear tests were carried out on the SANS CMT5305 universal material testing machine with the tensile and shear rate of $1 \mathrm{~mm} \cdot \mathrm{min}^{-1}$. The hardness was measured by HVS-30P micro-hardness tester under the conditions of test load, $50 \mathrm{~N}$, and holding pressure time, $10 \mathrm{~s}$.

\section{Results and discussion}

\subsection{Microstructure features at interface}

The microstructure at the bonding interface is shown in Fig. 3. It can be seen that a transition curve at the interface is relatively smooth and no obvious transition zone exists.

According to Ref. [19], when the bimetallic composite was prepared by diffusion composite method, higher preservation temperature and longer preservation time promoted further diffusion of alloying elements at the interface, then a transition 
(a)

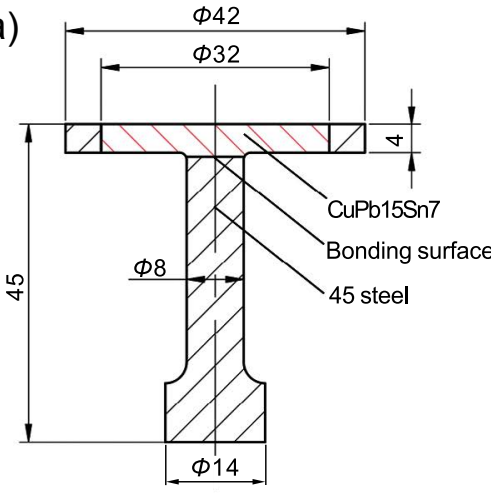

(b)

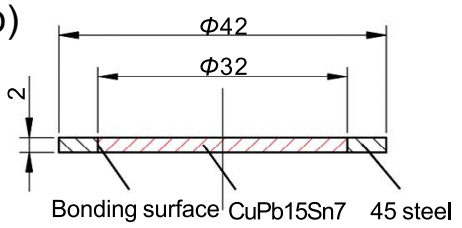

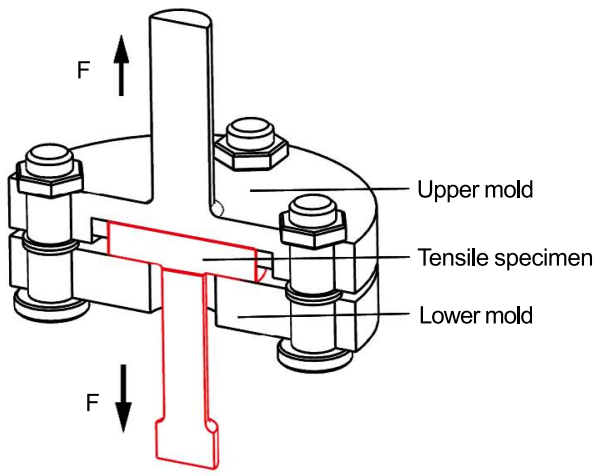

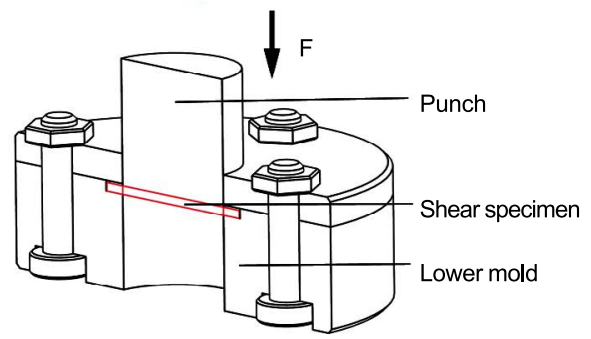

Fig. 2: Schematic diagram of tensile and shear specimens and fixtures: (a) tensile testing; (b) shear testing (unit: $\mathrm{mm}$ )

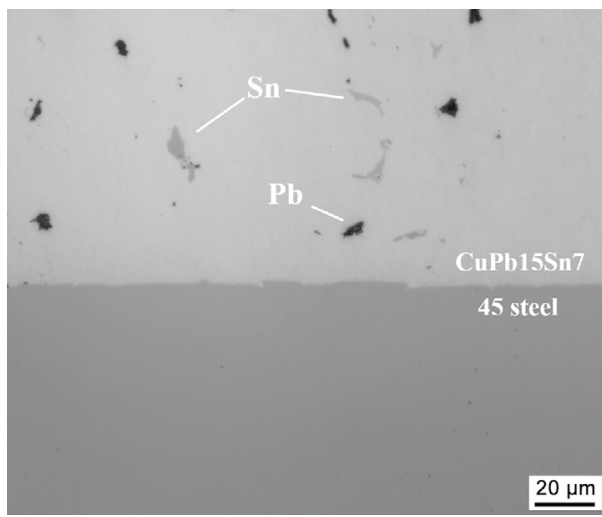

Fig. 3: Microstructure of bonding interface of bronze/steel composite

zone was formed. It was also pointed out that the transition zone would affect the bonding properties of composites, and brittle fracture was prone to be formed at the bonding interface. In this study, the formation of the transition zone is effectively avoided, and the microstructure and properties of the bonding interface are improved by using a low preservation temperature and a short preservation time. There are some dentate gaps and pits morphology on the surface of the 45 steel substrate, which is filled with lead bronze. The dentate gaps and pits morphology formed in the process of machining and surface treatment can increase the contact area at the bonding interface, and then reduce the relative slip and improve the bonding strength of the bimetallic composite.

\section{2 $\mathrm{Pb}$ element distribution in bronze region}

$\mathrm{Pb}$ element could increase the wear resistance of lead bronze. It's very important to control the particle size, distribution state, and content of $\mathrm{Pb}$ element. The distribution of $\mathrm{Pb}$ element in the bronze region after casting is shown in Fig. 4. $\mathrm{Cu}$ element precipitates in the form of dendrites, and the $\mathrm{Pb}$ element fills the space between the dendrites and presents as granular distribution during the cooling process. The overall distribution of $\mathrm{Pb}$ particles is relatively uniform, the particle size is mainly in the range of $1-20 \mu \mathrm{m}$, the average particle size is about $5.52 \mu \mathrm{m}$, but the average size of $\mathrm{Pb}$ particles before casting is $1-5 \mu \mathrm{m}$. This is because the $\mathrm{Pb}$ particles move faster and faster during the heat process, which causes the particles to rearrange, aggregate, and grow up correspondingly. When the heating and holding temperature reaches the melting point of lead bronze, the alloy will quickly melt into a liquid, and the $\mathrm{Pb}$ particles will be larger.

The results of inductively coupled plasma (ICP) analysis show that $\mathrm{Pb}$ content is $15.5 \%$ in the original specimen and $15.1 \%$ after casting, so the element content only is decreased by $0.4 \%$ in weight. The melting point of $\mathrm{Pb}$ is only $327^{\circ} \mathrm{C}$, which is much lower than that of bronze. After the bronze is melted and at the heat preservation stage, some $\mathrm{Pb}$ particles are easily vaporized and the $\mathrm{Pb}$ content decreases ${ }^{[18]}$, which will deteriorate the wear resistance of composites. Thus, a

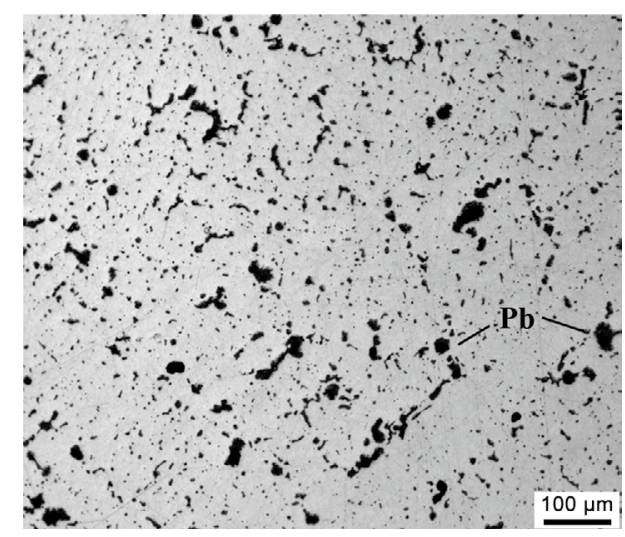

Fig. 4: Microstructure of bronze side of bronze/steel composite 
lower preservation temperature and shorter preservation time are essential to avoid the vaporization loss of $\mathrm{Pb}$.

\subsection{Alloy elements distribution at interface}

The diffusion behaviors of alloy elements at the bonding interface play an important role in the bonding state and interface strength of bimetallic composites. The bonding strength of the interface improves with the increasing of the alloy diffusion distance ${ }^{[24,25]}$. Figure 5 shows the results of element distribution and diffusion near the bronze/steel bonding interface. Figure 5(a) shows the EDS plane scanning results of the area of Fig. 5(b). Under high temperature and isobaric conditions, the difference of chemical potential gradient on both sides near the interface will drive atoms to exchange and diffuse to each other side during the heating and preservation stage. Meanwhile, Zhou et al. ${ }^{[26]}$ also pointed out that in the liquid-solid bonding process of bimetallic composite, when the temperature is heated to 0.5-0.75 times solid matrix's melting point, the diffusion coefficient along the grain boundary is about $10^{5}$ times the intracrystalline diffusion coefficient. This shows that the diffusion of alloy elements in the copper alloy along the grain boundary is easier than the diffusion among the grains at a heat preservation temperature of about $1,000{ }^{\circ} \mathrm{C}$ for the steel matrix containing many grain boundary defects. As a result, $\mathrm{Sn}$ and Ni elements in lead bronze are more easily diffused along the grain boundary of 45 steel, which leads to an increase in the content of $\mathrm{Sn}$ and $\mathrm{Ni}$ on the steel side. Since the Pb element is insoluble in the bronze, it is more likely to aggregate and grow up, then accumulate among the grains during heating and holding, so the diffusion of $\mathrm{Pb}$ into the steel side is not obvious.

The EDS results of yellow line in Fig. 5(b) are illustrated in Fig. 5(c). The results indicate that the content of each element changes significantly at the bonding interface from the steel side to the bronze side. Fe element changes from enrichment to depletion; incontrast, the content of $\mathrm{Cu}$ increases rapidly and then remains stable. $\mathrm{Pb}, \mathrm{Sn}, \mathrm{Ni}$, and other elements in the bronze side can still maintain a certain content after crossing the bonding interface, which demonstrates that the elements can diffuse through the bonding interface during the protective atmosphere casting process.

The XRD results of the bonding interface are illustrated in Fig. 6. It can be seen that the $\mathrm{Fe}$ and $\mathrm{Cu}$ elements near the interface still form Fe-based solid solutions, such as $\mathrm{FeCu}_{4}$, and the remaining peaks are $\mathrm{Fe}$ and $\mathrm{Cu}$, respectively, although the heat preservation time is relatively short. When $\mathrm{Fe}$ and $\mathrm{Cu}$ exist at the same time, the peak strength of $\mathrm{FeCu}_{4}$ is lower, so it can be inferred that the $\mathrm{FeCu}_{4}$ content at the interface is less. This also demonstrates that the protective atmosphere casting process generates fewer intermetallic compounds at the interface, which is effective in ensuring the structure property of the bonding interface.

\subsection{Tensile strength and fracture morphology}

The tensile testing results show that the average tensile strength of the composite is about 204.0 MPa, as illustrated in Fig. 7. (a)

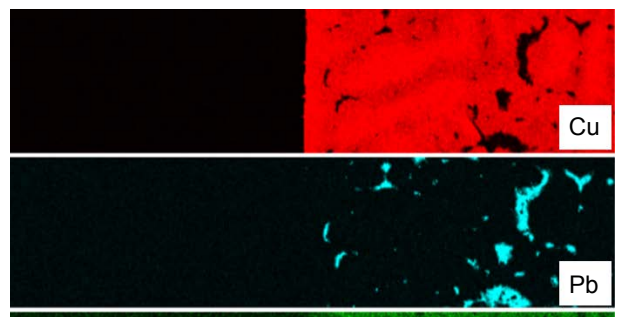

(b)

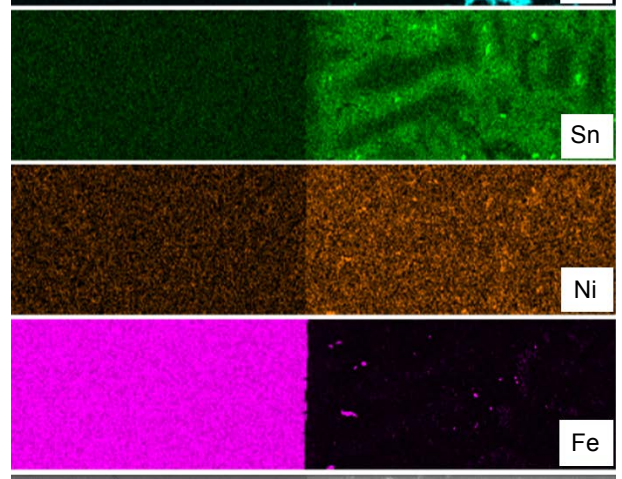

(c)
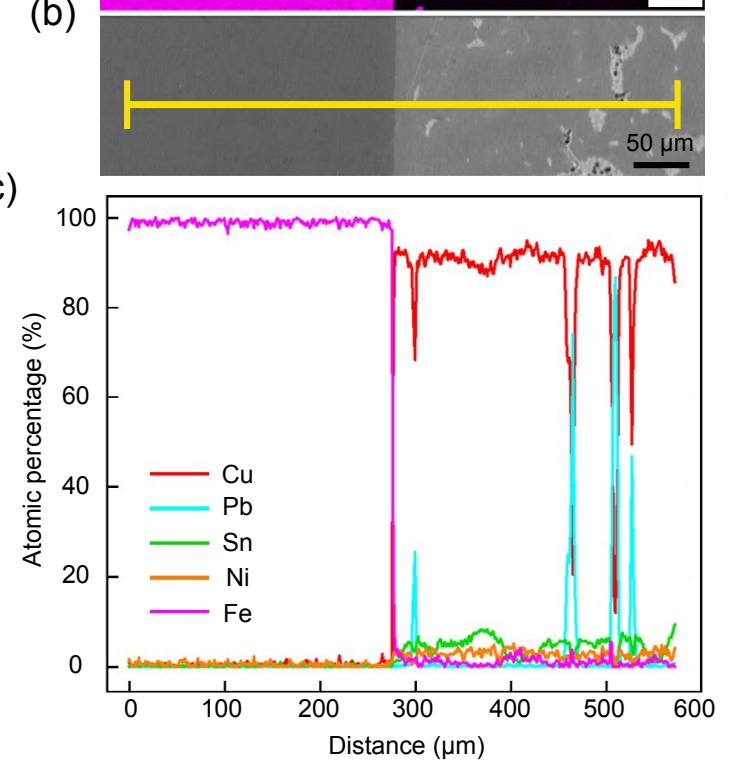

Fig. 5: Element distribution of bronze/steel bonding interface

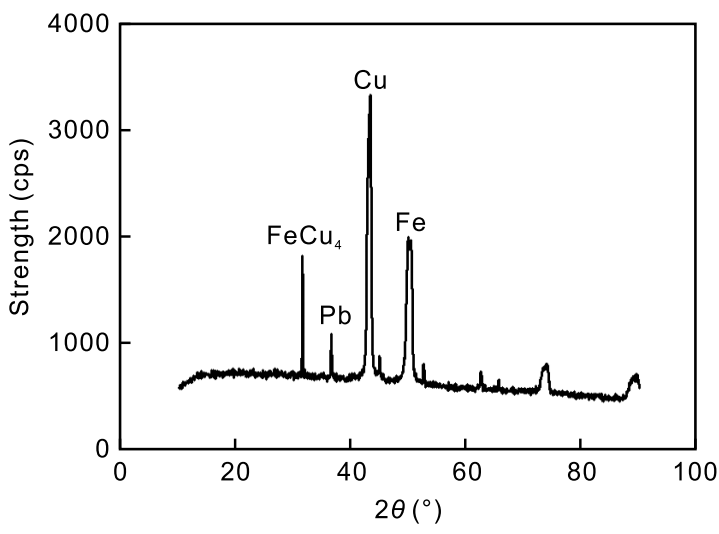

Fig. 6: XRD result at bonding interface

The morphology of the macro fracture and microstructures of the tensile specimen are shown in Fig. 8.

According to the fracture morphology as shown in Fig. 8(a), it can be known that the crack does not spread smoothly along the bonding interface after the sample cracks near the interface, 


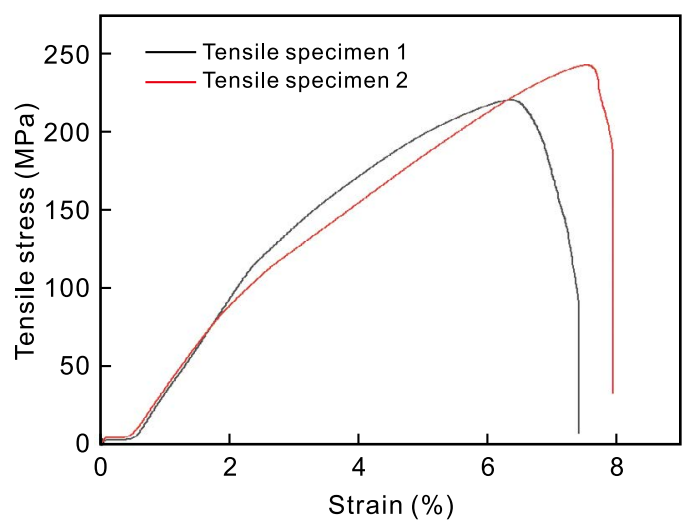

Fig. 7: Tensile stress-strain curves but extends up to the bronze layer at about $45^{\circ}$, and the fracture surface presents the morphology of "higher in the middle and lower at the margin" as a whole. There are no large bumps or pits on the fracture surface, which indicates that there is no obvious element segregation on the bronze side. At the same time, the fracture site is far away from the bonding interface and all of them are located in the bronze region rather than in the 45 steel. It can be seen that most of the fracture areas are relatively flat, rather than typical characteristics of ductile fracture, as shown in Fig. 8(b). Around the flat area, there are many structures with finer size and morphology (Area 1), which are observed at high magnification, as shown in Fig. 8(c). The morphology of the region is characterized by small dimples
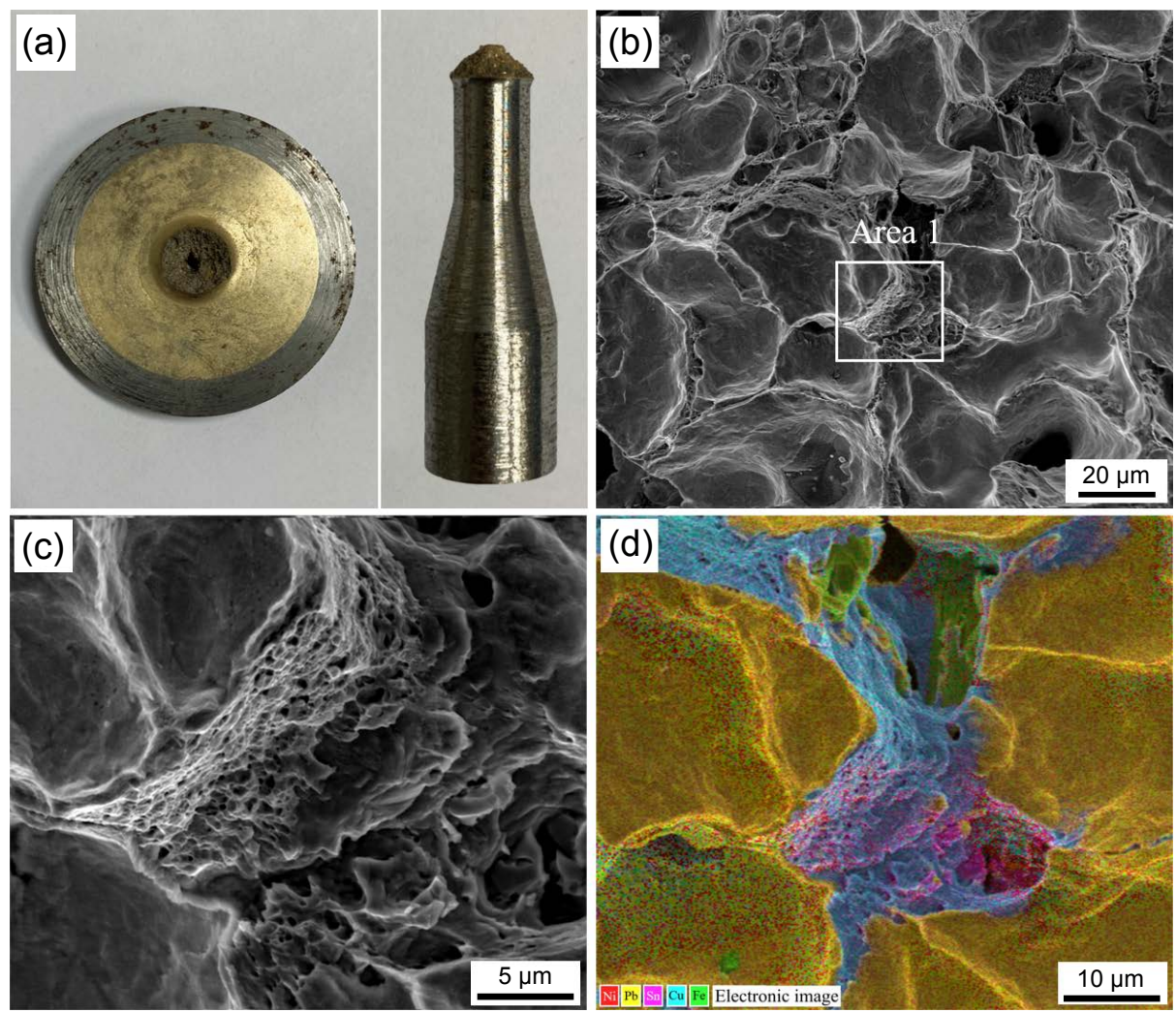

Fig. 8: Macro fracture and microstructure morphology of tensile specimen: (a) macro morphology; (b) microstructure of fracture surface; (c) magnified view of Area 1; (d) elements distribution on Area 1

and gullies. The EDS elements distribution scanning was performed on the Area 1 and its surroundings, with the result as shown in Fig. 8(d). The results indicate that the flat area of the fracture surface is mainly $\mathrm{Pb}$ element, and the surroundings are mainly $\mathrm{Cu}, \mathrm{Sn}$, and $\mathrm{Ni}$ elements.

The tensile fracture mechanism of the bronze/steel bimetallic composites is as follows. Although no obvious transition zone forms at the bonding interface during the protective atmosphere casting process, a small amount of $\mathrm{Cu}$ element diffuses into the 45 steel. The $\mathrm{Cu}$ element does not form carbides or impurity oxides with $\mathrm{C}, \mathrm{O}, \mathrm{Mn}$, or other elements in the steel, but dissolves in ferrite or austenite solid solution in an atomic state. In the cooling stage, a small and dispersed $\varepsilon$-Cu phase is precipitated, which greatly improves the stability and strength of the 45 steel substrate near the bonding interface ${ }^{[27]}$. The bonding interface strength of this area is greater than that of the bronze layer, which results in the fracture mainly occurring at the bronze side.

In the process of crack propagation, due to the low elongation, high brittleness, and insolubility in the bronze layer, $\mathrm{Pb}$ particles are fractured by tensile force, and the cracks easily extend along the particle fracture surface or particle edge, then resulting in a large number of $\mathrm{Pb}$ elements existing on the tensile fracture surface. There are a large amount of $\mathrm{Cu}$ and $\mathrm{Sn}$ elements around $\mathrm{Pb}$ particles because the substrate structure of lead bronze is mainly $\alpha$-phase $\mathrm{Cu}-\mathrm{Sn}$ solid solution, which is a kind of soft and wear-resistant alloy structure. The $\mathrm{Pb}$ particles are not dissolved in the matrix structure of the bronze, but are distributed in the form of dots in the $\alpha$-phase dendrite gaps. Therefore, the casting bronze layer presents the wear resistance 
structure of mixture of $\alpha$-phase and $\mathrm{Pb}$ particles. The ductile fracture will occur and dimple structures will form when the crack propagates through the $\mathrm{Pb}$ particles. This phenomenon of brittle-ductile alternating fracture eventually forms a tortuously rising fracture surface, which can avoid the phenomenon of peeling of the bronze layer.

\subsection{Shear strength and fracture morphology}

The shear test results show that the average shear strength of the composite is about 211.0 MPa, as shown in Fig. 9. The macro morphology of the shear sample and the microstructure of different fracture areas are shown in Fig. 10.

The shear fracture of bronze/steel bimetallic composite can be divided into two types, as shown in Fig. 10. The first fracture mode is the fracture of the bronze side, which is also the main fracture mode. It appears as a shear fracture of the $\mathrm{Pb}$ particle, as shown in Fig. 10(b) at low magnification. Under the action of shearing force and squeezing force, the $\mathrm{Pb}$ particles are broken to appear as a flat fracture surface. These surfaces are connected in large numbers to show a large area of flat fracture. There is a relatively fine-sized tissue area [Area 1 in Fig. 10(b)] near the fracture surface of $\mathrm{Pb}$ particles, which is observed at high magnification, as shown in Fig. 10(c). It

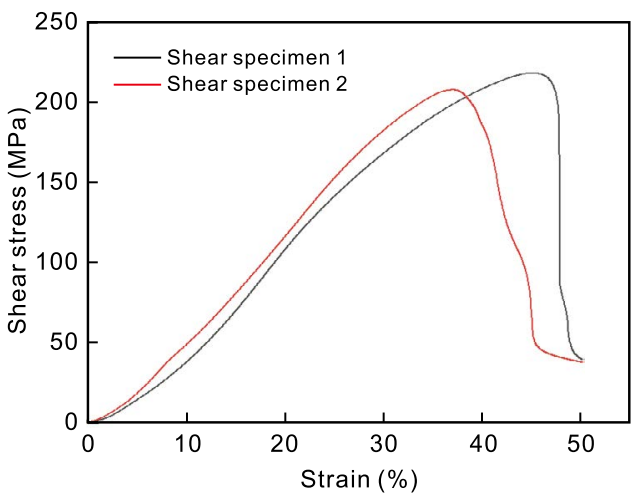

Fig. 9: Shear stress-strain curves
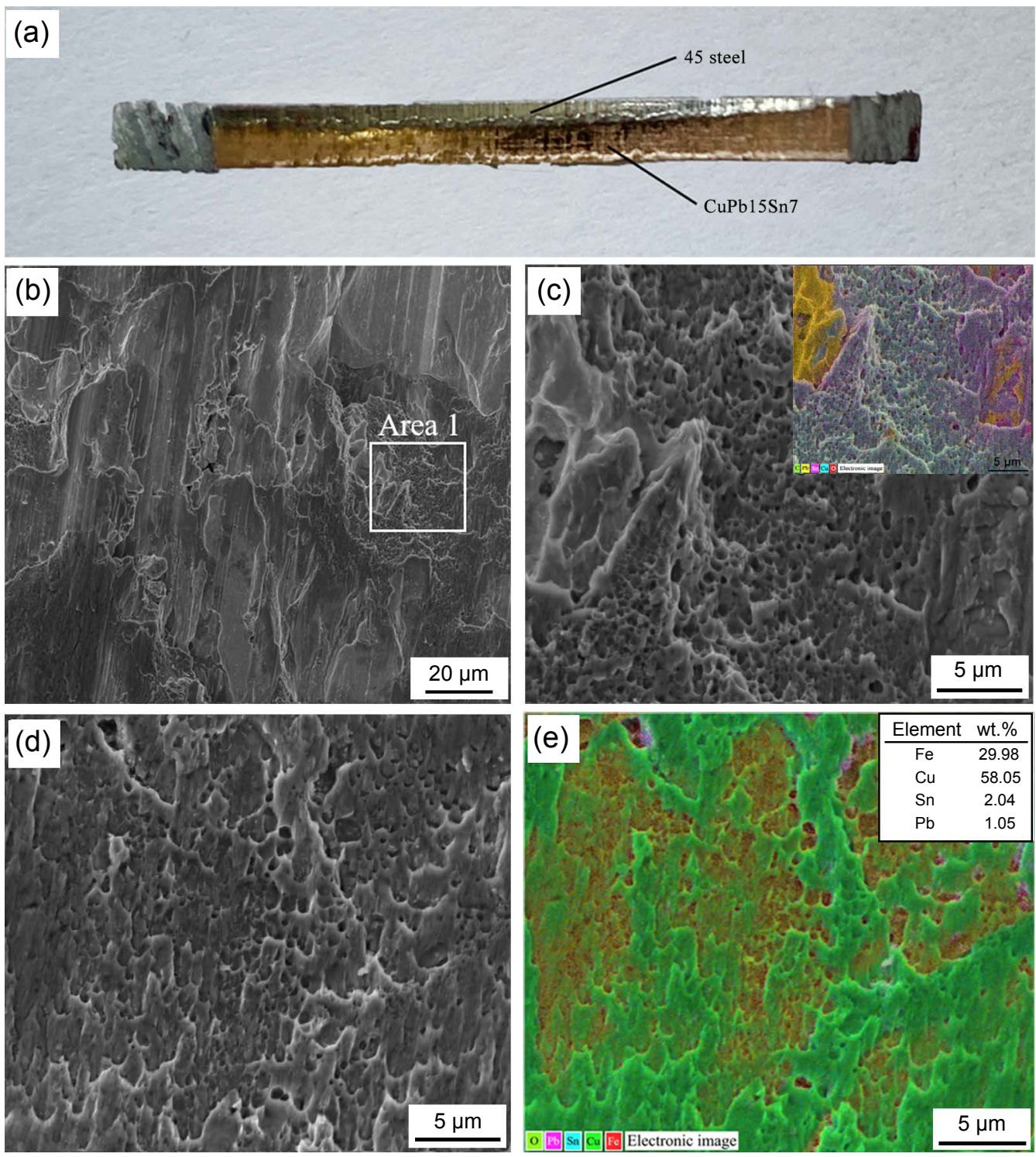

Fig. 10: Morphology of shear sample and microstructure of shear specimen fracture surface: (a) macro morphology; (b) fracture mode morphology of Pb particles; (c) magnified view of Area 1 in (b); (d) close to the bonding interface fracture mode morphology; (e) element distribution in (d) 
can be found that this area is characterized by a fine reticular or a parabolic dimple. The results of element analysis show that the distribution of elements in this area is similar to that in Fig. 8(d), and the main elements are $\mathrm{Cu}$ and $\mathrm{Sn}$. That is to say, the fracture surface of the shear specimen is characterized by the fracture of $\mathrm{Pb}$ particles and the ductile fracture of the surrounding $\mathrm{Cu}$-Sn solid solution structure, which also confirms the fracture analysis results of tensile fracture specimens.

Figure 10(d) shows the second fracture mode of shear fracture specimen. Under the action of shear stress, the bronze on the surface of 45 steel is plastically deformed and torn off, forming tearing prismatic morphology rather than massive fracture of $\mathrm{Pb}$ particles. Figure 10(e) shows the element distribution corresponding to Fig. 10(d). The fractures are mainly $\mathrm{Cu}$ and $\mathrm{Fe}$ elements, and the element content ratio is about 2:1. Therefore, it can be inferred that this fracture mode mainly occurs close to the bronze/steel bonding interface. Combined with the above analysis of tensile fracture, because $\mathrm{Cu}$ is the main element at the fracture, there is no peeling separation at the steel-copper bonding interface, so the shear strength of the bronze/steel interface exceeds that of bronze.

Therefore, it can be inferred that the interfacial bonding strength of lead bronze/45 steel composite prepared by the protective atmosphere casting process is greater than that of bronze, and all of the fractures of the tensile/shear specimens appear on the bronze side. The fracture mode in the bronze side shows a combination of "brittle fracture + ductile fracture". During the tensile/shear fracture process, when the fracture crack extends to the $\mathrm{Pb}$ particles distributed in the bronze, the shear force will cause the $\mathrm{Pb}$ particles to fracture, and the cracks will easily extend along the particle fracture surface to form a flat morphology and brittle fracture. After passing through $\mathrm{Pb}$ particles, the soft $\mathrm{Cu}-\mathrm{Sn}$ solid solution structure is contacted, and the microstructure is torn to form a shallow network and gully-like dimples morphology, showing the morphological characteristics of the $\mathrm{Cu}-\mathrm{Sn}$ tissue wrapped $\mathrm{Pb}$ particles.

\subsection{Hardness distribution}

Micromorphology and hardness distribution of test points are shown in Fig. 11. It can be seen that the microhardness values are very different between the bronze region and the steel region, while the microhardness on the same side of the interface fluctuates slightly, except for Point 2 with a hardness value of only $45.9 \mathrm{HV}$. Its micromorphology shows the broken state of $\mathrm{Pb}$ particles. Compared with $\mathrm{Cu}$ element, $\mathrm{Pb}$ element is softer, so the microhardness in its vicinity is relatively low. When the hardness point hits the $\mathrm{Pb}$ particle or its nearby area, the $\mathrm{Pb}$ particle is prone to deform under pressure, and the hardness value of this point also decreases accordingly. In addition, the interface between the $\mathrm{Pb}$ particles and the $\mathrm{Cu}$ alloy matrix is weak. It is prone to deform and fall off during the hardness testing, resulting in a decrease in the hardness value of the corresponding area. The hardness of the bronze layer determines the wear resistance and service life of the bronze/steel composite. The original hardness of the bronze is about 100.0 HV, and the average hardness value of Points 1, 3, 4 , and 5 in the bronze area is about 105.0 HV. This is beceuse the $\mathrm{Pb}$ element is enriched and grows up during the casting process, and no obvious coarse $\mathrm{Pb}$ particles. The improvement of the hardness of the bronze region can ensure the high wear resistance of the bronze region. In general, the bronze region can meet the requirements of high wear resistance.
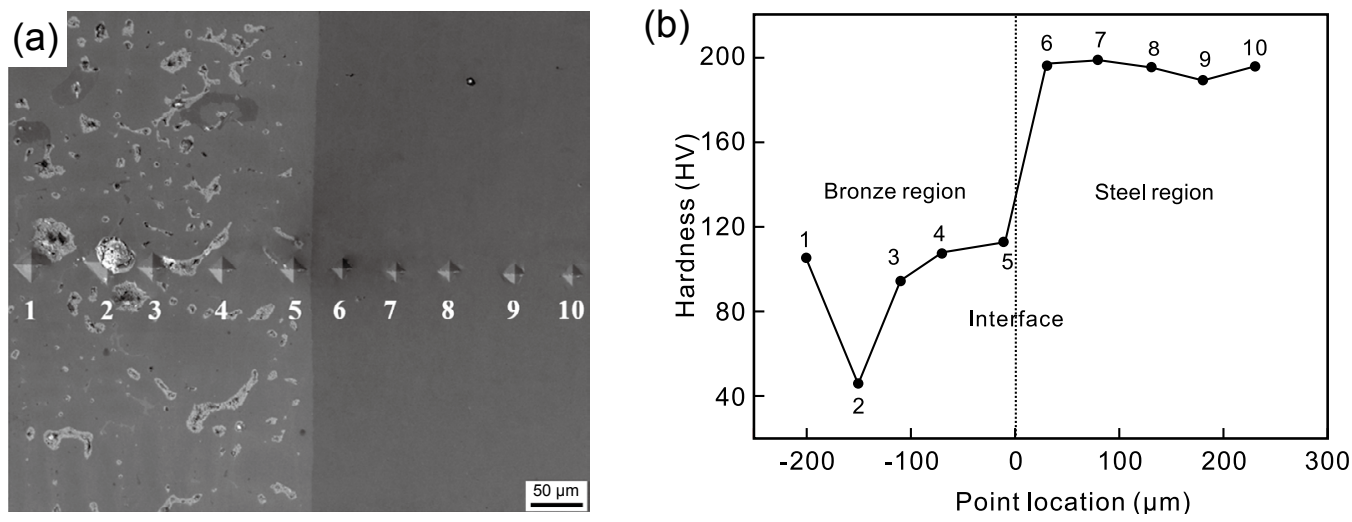

Fig. 11: Micromorphology (a) and hardness distribution curve (b) of hardness test point near copper-steel interface

\section{Conclusions}

In this study, the bronze/steel bimetallic laminated composite was prepared by the protective atmosphere casting method. The main conclusions are as follows:

(1) The lead bronze/45 steel bimetallic composite billets have no obvious transition zone at the interface. The $\mathrm{Pb}$ particles in the bronze region are evenly distributed, and vaporization of $\mathrm{Pb}$ is only $0.4 \%$ in weight. $\mathrm{Fe}, \mathrm{Cu}, \mathrm{Sn}, \mathrm{Ni}$, and other alloy elements diffuse into both layers at the bonding interface. The bronze/steel achieves solid and compact metallurgical bonding.

(2) The maximum tensile strength and shear strength are 204.0 MPa and 211.0 MPa, respectively. The hardness of the bronze layer exceeds the original hardness of bronze 
$(100.0 \mathrm{HV})$. Moreover, the fracture failure occurs at the bronze side near the bonding interface. The fracture mode is a comprehensive fracture mode with the interaction of brittle fracture of $\mathrm{Pb}$ particles and ductile fracture of $\mathrm{Cu}$ Sn solid solution. These characteristics demonstrate the prepared bimetallic composite has excellent comprehensive performance.

\section{References}

[1] Sun Y F, Fujii H, Takaki N, et al. Microstructure and mechanical properties of dissimilar Al alloy/steel joints prepared by a flat spot friction stir welding technique. Materials \& Design, 2013, 47: 350-357.

[2] Guo S, Zhou Q, Kong J, et al. Effect of beam offset on the characteristics of copper/304 stainless steel electron beam welding. Vacuum, 2016, 128: 205-212.

[3] Li Z, Zhao J W, Jia F H, et al. Interfacial characteristics and mechanical properties of duplex stainless steel bimetal composite by heat treatment. Materials Science and Engineering: A, 2020, 787: 139513.

[4] Xiao X F, Ye S P, Yin W X, et al. HCWCl/carbon steel bimetal liner by liquid-liquid compound lost foam casting. Journal of Iron and Steel Research, International, 2012, 19(10): 13-19.

[5] Chen $\mathrm{S} \mathrm{H}$, Huang $\mathrm{J} \mathrm{H}$, Xia J, et al. Influence of processing parameters on the characteristics of stainless steel/copper laser welding. Journal of Materials Processing Technology, 2015, 222: 43-51.

[6] Liu X P, Bai R S, Uy B, et al. Material properties and stressstrain curves for titanium-clad bimetallic steels. Journal of Constructional Steel Research, 2019, 162: 105756.

[7] Jiang W M, Fan Z T, Li G Y, et al. Effects of zinc coating on interfacial microstructures and mechanical properties of aluminum/steel bimetallic composites. Journal of Alloys and Compounds, 2016, 678: 249-257.

[8] Jiang Z Y, Gao X J, Li S L, et al. Interface analysis and hot deformation behaviour of a novel laminated composite with high-Cr cast iron and low carbon steel prepared by hot compression bonding. Journal of Iron and Steel Research, International, 2015, 22(5): 438-445.

[9] Onuike B, Bandyopadhyay A. Bond strength measurement for additively manufactured Inconel 718-GRCop84 copper alloy bimetallic joints. Additive Manufacturing, 2019, 27: 576-585.

[10] Bandyopadhyay A, Heer B. Additive manufacturing of multimaterial structures. Materials Science and Engineering: $R$ : Reports, 2018, 129: 1-16.

[11] Gupta R, Srivastava S, Kumar N K, et al. High leaded tin bronze processing during multi-directional forging: Effect on microstructure and mechanical properties. Materials Science and Engineering: A, 2016, 654: 282-291.

[12] Liu B X, Wei J Y, Yang M X, et al. Effect of heat treatment on the mechanical properties of copper clad steel plates. Vacuum, 2018, 154: 250-258.
[13] Lee J E, Bae D H, Chung W S, et al. Effects of annealing on the mechanical and interface properties of stainless steel/ aluminum/copper clad-metal sheets. Journal of Materials Processing Technology, 2007, 187-188: 546-549.

[14] Yamazaki T, Shibuya T, Jin C J, et al. Lining of hydraulic cylinder made of cast iron with copper alloy. Journal of Materials Processing Technology, 2006, 172(1): 30-34.

[15] Torabi $H$, Arghavanian R. Investigations on the corrosion resistance and microhardness of $\mathrm{Cu}-10 \mathrm{Sn} / \mathrm{SiC}$ composite manufactured by powder metallurgy process. Journal of Alloys and Compounds, 2019, 806: 99-105.

[16] Bhuyan P, Alam S N, Panda D, et al. Synthesis and characterization of $\mathrm{Cu}-\mathrm{Fe}_{3} \mathrm{Al}$ composites using powder metallurgy route. Materials Today: Proceedings, 2017, 4(2, Part A): 213-223.

[17] Wu D, Yang L, Shi C D, et al. Effects of rolling and annealing on microstructures and properties of $\mathrm{Cu} / \mathrm{Invar}$ electronic packaging composites prepared by powder metallurgy. Transactions of Nonferrous Metals Society of China, 2015, 25(6): 1995-2002.

[18] Liu R T, Xiong X, Chen F S, et al. Tribological performance of graphite containing tin lead bronze-steel bimetal under reciprocal sliding test. Tribology International, 2011, 44(2): 101-105.

[19] Zou J T, Li S L, Wei Y N, et al. Research of the bonded interface of Cu9Al4Fe/1Cr18Ni9Ti stainless steel bimetallic composite. Vacuum, 2017, 146: 266-273.

[20] Zhang X, Wu D, Yang L, et al. Microstructures and properties of $\mathrm{Cu} / \mathrm{Ag}$ (Invar) composites fabricated by powder metallurgy. Transactions of Nonferrous Metals Society of China, 2017, 27(8): 1759-1766.

[21] Yilmaz O, Çelik H. Electrical and thermal properties of the interface at diffusion-bonded and soldered 304 stainless steel and copper bimetal. Journal of Materials Processing Technology, 2003, 141(1): 67-76.

[22] Sabetghadam H, Hanzaki A Z, Araee A, et al. Microstructural evaluation of $410 \mathrm{SS} / \mathrm{Cu}$ diffusion-bonded joint. Journal of Materials Science \& Technology, 2010, 26(2): 163-169.

[23] Prasad B K. Sliding wear behaviour of bronzes under varying material composition, microstructure and test conditions. Wear, 2004, 257(1): 110-123.

[24] Liu B X, Wang S, Fang W, et al. Microstructure and mechanical properties of hot rolled stainless steel clad plate by heat treatment. Materials Chemistry and Physics, 2018, 216: 460467.

[25] Wang S, Liu B X, Chen C X, et al. Microstructure, mechanical properties and interface bonding mechanism of hot-rolled stainless steel clad plates at different rolling reduction ratios. Journal of Alloys and Compounds, 2018, 766: 517-526.

[26] Zhou Y H, North T H. Numerical model for the effect of grain boundaries on the total amount diffused. Acta Metallurgica et Materialia, 1994, 42(3): 1025-1029.

[27] Hsu C H, Lin K T. A study on microstructure and toughness of copper alloyed and austempered ductile irons. Materials Science and Engineering: A, 2011, 528(18): 5706-5712. 